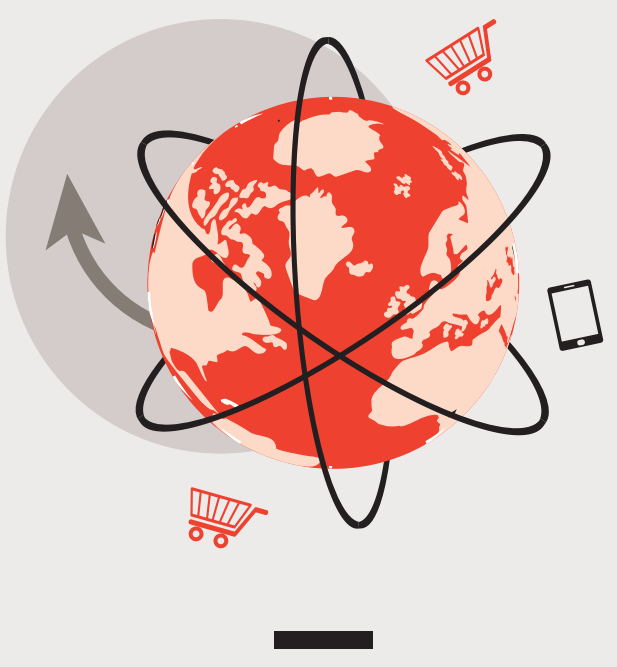

ABOUT EBAY

eBay Inc. is a global commerce leader, which includes the Marketplace, StubHub and Classifieds platforms. Collectively, eBay Inc. connects millions of buyers and sellers around the world. The technologies and services that power the eBay platforms are designed to enable sellers worldwide to organize and offer their inventory for sale, and buyers to find and purchase it, virtually anytime and anywhere. eBay Inc. employs approximately 14,100 people globally. The eBay Marketplace platforms include the online marketplace ebay.com, its localized counterparts like ebay.de and the eBay mobile apps, which are among the world's largest and most vibrant marketplaces for discovering great value and unique selection. In 2017, goods worth $\$ 84$ billion were traded globally on the eBay marketplace.

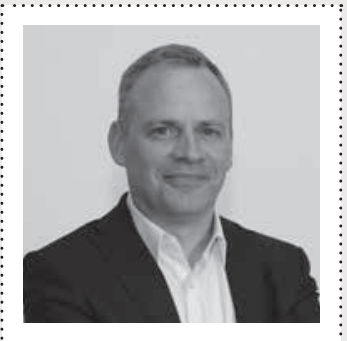

ABOUT EBEN SERMON

Eben Sermon is responsible for the German eBay marketplace, one of the largest global markets for eBay, since May 2017. He joined eBay in 2007 and held a number of leadership positions since in Marketing as well as Cross Border Trade. In August 2015 he took over the role of Vice President Greater Europe, overseeing the eBay businesses in France, Italy, Spain as well as the marketplaces in Russia and Turkey. Prior to joining eBay, he held various leadership roles at British Airways. Eben is British and studied Business Administration and French at the University of Wales, Aberystwyth.
THE INTERVIEWER

Prof. Werner Reinartz conducted the interview in November 2018. 


\title{
eBay: Transforming an Auction House into a Retailing Platform
}

\author{
Interview with Eben Sermon, Vice President eBay Germany
}

\author{
Auction thrill for everybody - no matter if you are the buyer or seller - that's what has \\ made eBay famous and attractive in its early years. The internet pioneer was already born in \\ the last millennium and has revolutionized the consumer to consumer business. Originally \\ the first supra-regional, electronic flea market, eBay has evolved into one of the world's \\ largest retailing platforms. A lot has happened and the auctions that once constituted the \\ core of the brand are more of a sideshow nowadays. In the following interview, Eben Sermon, \\ Vice President of eBay Germany, explains how the brand has been reinventing itself and \\ talks about eBay's innovations within the highly competitive field of e-commerce.
}

MIR: eBay is one of the venerable Internet pioneers - basically being synonymous with the online auction format. How has the auction format and your retailing business model evolved since then?

EBEN SERMON: It is true that in the beginning eBay was particularly well-known for auctions. This has, however, changed significantly. Today roughly $80 \%$ of our business is fixed price trade with brand new items. A series of fundamental investments have been made during the last years to strengthen eBay in what is a very competitive industry. The focus of these investments has been to offer buyers the greatest possible selection of inventory from all over the world, with the most engaging shopping experience, whilst strengthening the platform for sellers. Much has been done already and there remains lots more to do.

MIR: The success of the platform business model is being discussed vividly these days. What are the success factors for a marketplace such as eBay?
EBEN SERMON: In Germany, platforms account for more than $50 \%$ of all online sales and are growing up to four times faster than other e-commerce players. They play an increasingly important role and work as an ecosystem. The strength of a good marketplace lies in the extent of the inventory range. For consumers this makes marketplaces a one-stop shop for all of their retail needs. This collection of buyers then subsequently makes it attractive for sellers. The more a market place grows, the more competitive it gets in terms of price and variety. The key, though, lies in the way that marketplaces are able to collect data and insights into consumers and inventory trends and in using these to create vibrant and personalized shopping experiences.

MIR: What are your priorities to remain attractive for consumers and to become even more attractive?

EBEN SERMON: Customers demand more and more convenience and engagement. Today about $60 \%$ of Germans expect delivery in two days or less. And according to $\mathrm{DHL}$, fast shipping is 


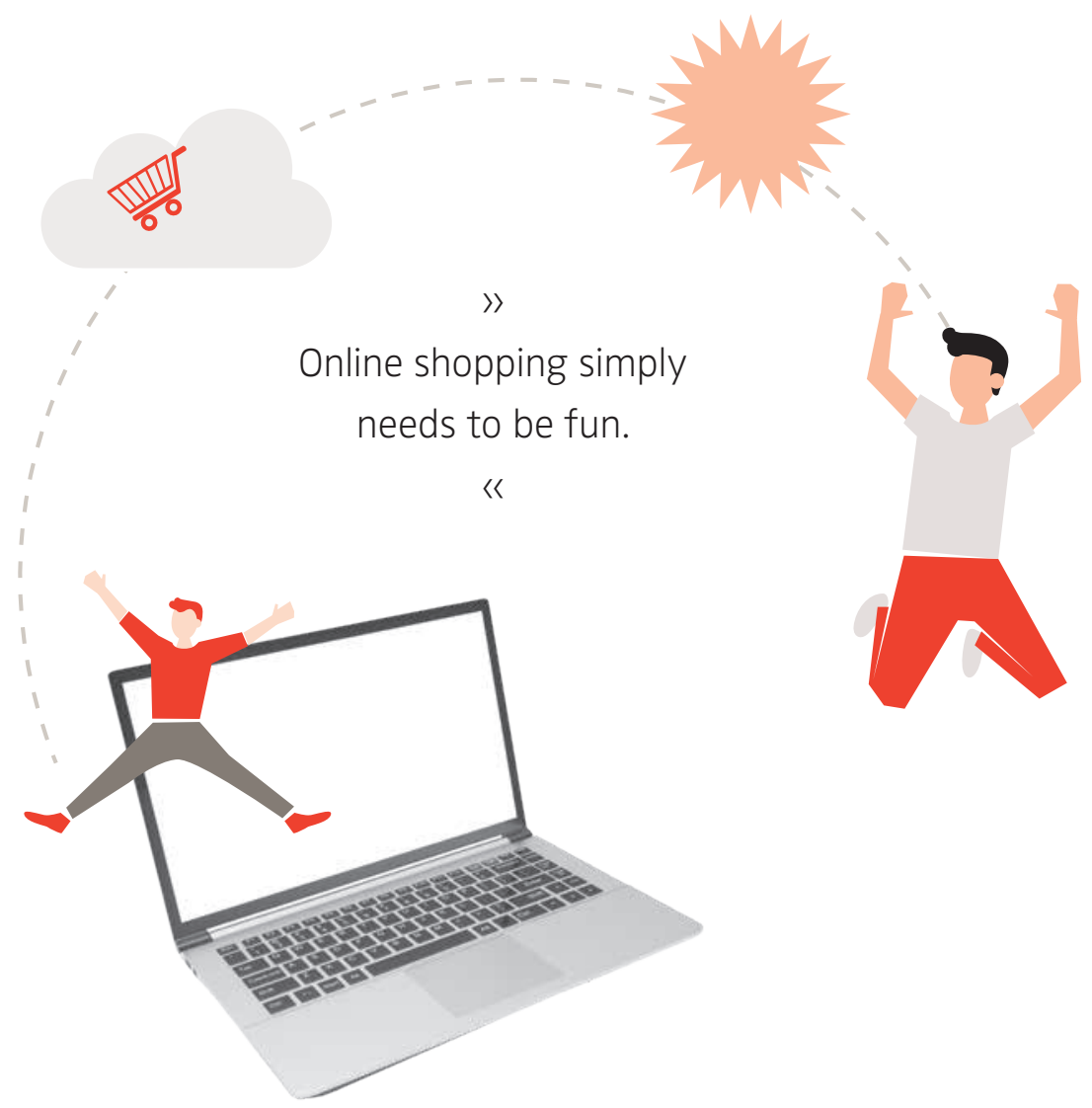

decisive for $80 \%$ of e-commerce consumers. In addition, Germany also has the highest expectations of returns. Some $15 \%$ of all parcels are sent back. This is about three times more than in the US. But convenience is also about consumer's desire for experiences that are personalized and about convenience in choosing and ordering products. The challenge for all in eCommerce is delivering on high expectations of convenience but also doing it in a way that shows off one's inventory in increasingly engaging ways. Online shopping simply needs to be fun. There are apps to shop by video and others that are gamified. But most important is knowing how to remain flexible on these two axes - convenience and engagement - for different shopper segments. For instance, a Young Value Shopper can have very different expectations from a mother of three children.

MIR: What precisely do you do to score on convenience and to exceed other platforms?

EBEN SERMON: With regard to convenience, one of the main building blocks is our loyalty program eBay Plus which provides premium shipping, free returns, premium customer support and exclusive eBay Plus offerings to buyers. In 2018, the number of items eligible for eBay Plus has doubled and we are working to further increasing it. Our logistics initiatives
eBay Fulfillment and eBay Versand are central to this, as they allow sellers to meet the standards of the eBay Plus program. eBay Fulfillment enables together with our partners FIEGE and Hermes next-day-delivery for purchases that come in until $6 \mathrm{pm}$ on a day. eBay Versand offers smaller sellers fast delivery solutions at attractive prices for all channels. In partnership with DPD, participating retailers agree on a suitable daily pick-up window that is always later than $2: 30 \mathrm{pm}$ to ensure that many orders can be delivered the next day. We are currently testing both of these new services in a beta version with selected eBay sellers.

MIR: And how do you make sure that your shopping experience keeps getting more engaging?

EBEN SERMON: For example, we recently launched image search in Germany to power searching and shopping with images on mobile devices. Shoppers can take a photo or use an existing photo from their camera roll of an item they want to purchase and enter it into the search bar. eBay will then surface listings that are a close match or visually similar - all enabled by artificial intelligence and machine learning. We are also experimenting with conversational commerce and virtual reality. Conversational commerce enables eBay to let buyers find the 
desired item in the Google assistant "Ask eBay" as if they had asked a friend about it. And with regard to VR, StubHub has been pioneering a feature that lets buyers of 4 event tickets see a 360-degree view from their chosen seat. Within a short time of its launch, a large percentage of all ticket purchasers are using this technology.

\section{MIR: So, new technologies are the key to success?}

EBEN SERMON: Yes, but the basics need to be taken care of as well. In Germany, for instance, we have established a local engineering team to really get the site working perfectly in the German language. As a non-native German speaker, I have quickly understood the importance of getting it right on the site. Some of the things we address here, might seem small, e.g. to ensure that German "Umlaute" are handled in the right way - yet, they bring quite a lot of additional opportunity to the business.

MIR: Before you talked about different shopper segments with their different needs and mentioned Young Value Shoppers. How do you address the specific needs of this segment?

EBEN SERMON: The younger millennial shoppers below 35 are driving up eBay.de's total number of active buyers. In 2018, growth in new buyers on eBay.de accelerated by 16 percentage points compared to 2017 . We are achieving this acceleration at a time where growth of online shoppers in Germany in general is slowing. So, this segment is of particular importance. The work here has included the launch of our "Unter 20 Euro" experience on eBay.de as well as a beta version of Catch - our new mobile-focused and browse-based shopping experience that sits off-eBay. The Catch platform addresses the Younger Value Shoppers who want to discover the newest and hottest products at great prices, shop spontaneously and who have high expectations for service and engaging, fun experiences.

MIR: As a retailing platform you are handling a two-sided market and you have to be attractive for the other side - the sellers -as well. Which innovative services do you offer to your eBay sellers?

EBEN SERMON: For sellers, a particular focus has been on new advertising formats, new promotion tools as well as new tools to manage and grow their business. The start of the introduction of the new payments experience in the US is also highly relevant for sellers as they will benefit from a simplified pricing structure, more predictable access to their funds, and better visibility into sales and payouts.
MIR: Do you also see segments on the seller side? Are there segments that are more critical for your growth perspectives than others?

EBEN SERMON: More than in any other market in Europe, there is a strong base of SMBs in Germany, aka the "Mittelstand", which includes brands, manufacturers and retailers. Of these roughly 3.6 million SMBs, more than two thirds do not sell online and less than $10 \%$ export online. Which is why one of the core issues for us in Germany is how to best support SMBs and their particular needs and challenges. We have made clear improvements in our inventory offering - including the launch of more than 60 brands and retailers in 2018 alone. Our mission is to be a strong and true partner to brands and retailers of all sizes - including the many smaller retailers and local store owners. Different from other market players, we will never compete with the sellers on our site. The success of our sellers is our success.

MIR: Especially for small merchants, eBay may provide a lot of value. How does eBay unlock that potential?

EBEN SERMON: eBay provides tools to allow easy upload of inventory and to generate data insights. We have, for instance, developed a Seller Hub which is designed to offer in one place all you need to sell and grow, and we are working to add new features continuously. In Seller Hub, sellers of any size find the

$\gg$

Different from other market players, we will never compete with the sellers on our site. The success of our sellers is our success.

$\ll$

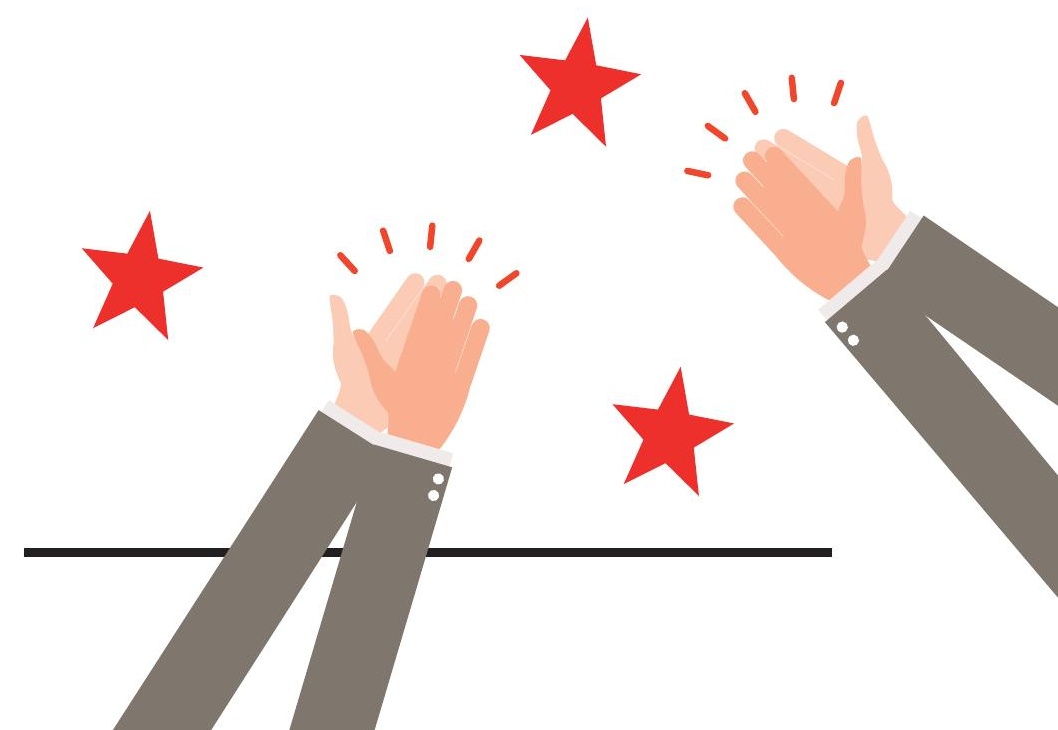


tools that allow them to analyze their business and to promote their inventory - for example to highlight listings in search with "Promoted Listings" and to offer volume discounts like the newly launched Multi-buy feature. This has recently been supplemented with specific support for shipping and fulfilment so that even small sellers can compete with 1-2 day delivery.

MIR: You described your market place as an ecosystem. Besides the sellers and the buyers, are there any other exciting new partners and cooperations that you can tell us about?

EBEN SERMON: In general, we believe very much in the power of partnerships. There are many areas where we see the potential for partnership - and all aimed at fulfilling our vision to delight the customer and win on both convenience and engagement. In 2018, our partnerships have mostly focused on convenience. Examples are our eBay Fulfillment and eBay shipment offerings in partnership with Fiege Logistik, Hermes, plentymarkets and DPD. Our partnership with idealo allows the direct purchase of eBay items on idealo. Our partnerships with local cities help buyers find local eBay sellers and inventory in their neighborhood. Another concrete example is our partnership with Werkstars. It enables us to offer local tire installation services to consumers who buy new tires on eBay. And through our partnership with AXA we are able to offer insurance to eBay Plus members. My diary is filled with partnership discussions related to 2019 . You should definitively watch this space for what we might do next, including an additional focus on partnerships and experiences aimed at driving deeper engagement.

MIR: How do technology developments such as artificial intelligence $(\mathrm{Al})$, machine learning, or virtual reality impact you and your offering?

EBEN SERMON: We are excited about the rapid development of technology and are continuously testing solutions, especially in the Al field. With the acquisition of specialist Al focused companies AppTek, Expertmaker and SalesPredict we have reinforced our activities. We use Al to improve eBay's "Best Match" search algorithm that drives better discoverability for individual items from the vast inventory and learns how customers search and browse - enabling them to faster find what they are looking for. Recently we have enabled users to shop by image in eBay's apps. Further, we machine-translate items so that shoppers all over the world can understand the items descriptions in their language. Combining all our data through Al has also helped eBay start to structure our one billion of items into grouped products. Other technologies such as Virtual Reality are exciting
〉)

\section{Today at eBay about $64 \%$ of the trading volume is touched by mobile somewhere in the purchase flow.}

$\ll$

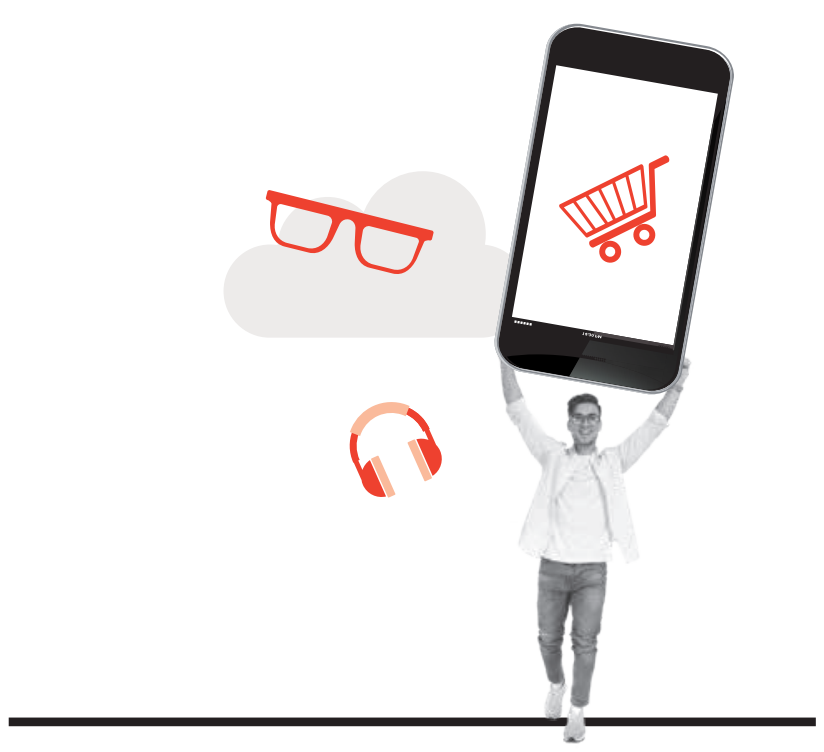

but more nascent in use cases. One example of implementation has been our experimentation with VR in our tickets business Stubhub, which I have mentioned before.

MIR: Do eBay customers increasingly use their mobile phones for their purchases?

EBEN SERMON: In the market, about $69 \%$ of the German smartphone owners use their mobiles for shopping and app-based shopping sessions are surging. Of course, we notice this trend as well. The value of articles sold via mobile device accounts for 12.7 billion US dollars for eBay worldwide in the third quarter of 2018 alone. Today at eBay about $64 \%$ of the trading volume is touched by mobile somewhere in the purchase flow and eBay's app is one of the most popular shopping apps in Germany.

MIR: What is the impact of this trend to mobile on your business?

EBEN SERMON: It is huge. We had to strongly adapt the way we operate as a company. Marketing budget allocation, promotions, browse experiences, usability and competition moni- 
toring have all needed to change. eBay has been very focused on improving the usability of our mobile experiences. This year we have launched a new mWeb experience, the image search function in our eBay app and we introduced Catch, our new mobile-oriented shopping platform for Young Value Shoppers. We have also simplified the listing flow for items via mobile. At the same time, we are rapidly testing different new kinds of engagement for mobile users.

MIR: Apart from these technological challenges, are there additional focus areas for eBay in Germany?

EBEN SERMON: eBay's position in the German market remains strong and is strengthening. The eBay brand is, however, still somewhat misunderstood and this is something we are keen

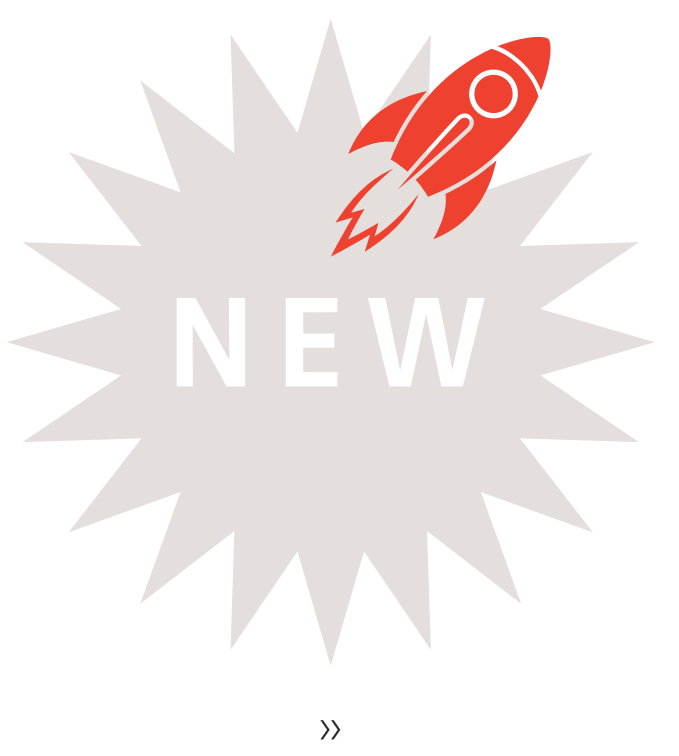

Our business has changed a lot in the last decade and today $80 \%$ of our items are new.

《

to address with both buyers and in industry. Our business has changed a lot in the last decade and today $80 \%$ of our items are new. This is a key thing we need to address in our brand work and this is what we do. We have a huge opportunity to help people understand what the eBay brand stands for today. We are offering an incredible breadth and depth of inventory from both professional and private sellers - covering the entire product life cycle, from new in-season merchandise, last season items, refurbished merchandise, vintage items or completely unique articles- enabling everybody to find exactly the item he or she is looking for.

MIR: What will the future of retailing hold for eBay Germany? Is eBay well positioned in this highly competitive environment?

EBEN SERMON: Today eBay is the number 38 brand in the world according to Interbrand and has some 177 million active buyers located in 190 markets. 1.1 billion products are for sale on the platform worldwide - this makes it one of the most vibrant marketplaces in the world. More than 17 million of these active buyers are located in Germany and this number is on the rise. We also have a strong position with brands, retailers and SMES in Germany - many of them choosing to trade only on eBay because of our general commitment not to compete with our partners. Germany is particularly interesting for eBay because of its rapidly expanding portfolio. Beside the eBay marketplace and the newly launched Catch site, we also operate the platforms eBay Kleinanzeigen, brands4friends, mobile.de and StubHub. eBay marketplace and eBay Kleinanzeigen combined account for some $42 \%$ of all internet shopping minutes that people spend online in Germany. This scale allows us to more aggressively tackle both local and global opportunities in a way that no other marketplace can do. You will see us leverage this more in the coming year.

MIR: We are thrilled to observe what will be coming. Thank you very much for granting us insight into the eBay universe. We wish you continued success with all your new ventures!

I. 